\title{
La identidad gay: una identidad en tensión Una forma para comprender el mundo de los homosexuales
}

\author{
César Octavio González Pérez
}

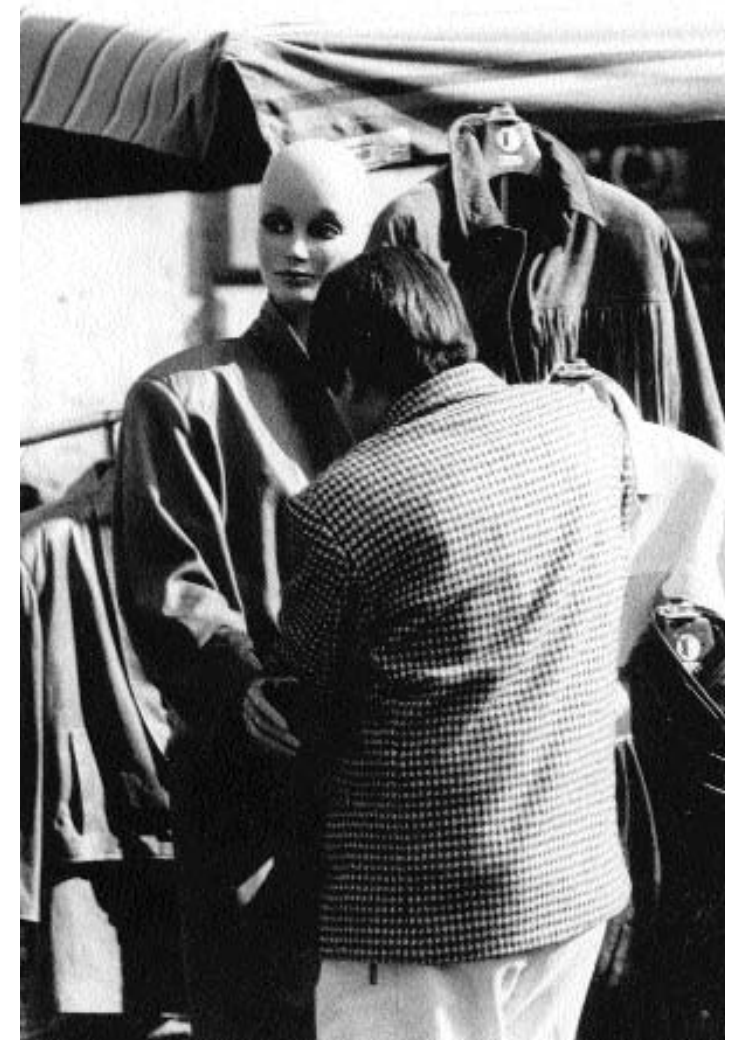

Vistiéndote, Jorge Acevedo

CÉSAR OCTAVIO GONZÁLEZ PÉREZ: Licenciado en Comunicación Social de la Universidad de Colima y candidato a maestro en Antropología Social por el Centro de Investigaciones y Estudios Superiores en Antropología Social-Unidad Occidente (CIESAS).
$\mathrm{L}$ A IDENTIDAD GAY es de aparición reciente y ha permeado las sociedades a nivel global. Lo gay es algo más que hombres o mujeres que sostienen relaciones sexuales con individuos de su mismo sexo, es todo un entramado que abre la puerta para reflexionar sobre el género y las construcciones sociales que se han armado en torno a las homosexualidades. Utilizo el término en plural, pues como veremos en esta exposición, la homosexualidad puede operar en formas diferentes y diversas, de modo tal que lo gay corta el mundo homosexual, tomando como referente una parte de éste y mostrándonos sus múltiples caras.

En este ensayo propongo una alternativa teórica para comprender las homosexualidades. Para ello, centro mis reflexiones en el surgimiento de la identidad gay como una categoría autoadscrita de los homosexuales para confrontar colectivamente sus espacios y territorios. Mi intención es mostrar cómo la identidad gay puede operar en la representación de un espacio simbólico que se circunscribe en un campo social de "lo sexual".

\section{EL GÉNERO COMO UNA CONSTRUCCIÓN SOCIAL. ¿ERES HOMBRE O MUJER?}

Jeffrey Weeks (1998) dice que atribuir los significados sexuales y las relaciones sociales a las diferencias biológicas y genéticas es caer en el esencialismo, pues resulta 
exagerado culpar a las hormonas y a los cromosomas de todas las prácticas sociales realizadas por los humanos. Si las personas actuaran según un mapa genético, ¿cómo explicaríamos las diferencias culturales entre las sociedades e, incluso, entre los mismos individuos?

Las hormonas y la genética determinan la anatomía y fisiología de los seres vivos pero no son decisivas en la configuración de las diferencias sociales. La familia, el matrimonio y, en especial, el erotismo, no pueden reducirse a perspectivas biologizadas y reproductivas. Por ejemplo, el matrimonio no es exclusivamente heterosexual y monógamo. Sin detallar las diferentes formas de matrimonio poligámico o poliándrico que existen en culturas diferentes a las que concilian con la tradición judeocristiana, basta mencionar que, entre los "nuers", las mujeres se casan con mujeres.

La socialización erótica es versátil y no delimitada a un gen. En este sentido, Jeffrey Weeks (1998) establece que la sexualidad existe como una presencia social e histórica, donde las posibilidades biológicas y mentales se amalgaman. La sexualidad, por el hecho de tratarse de algo social, sufre cambios. Los seres humanos no por contar con un pene o con una vagina están determinados en sus prácticas sociales y/o eróticas: la verdad es que los seres humanos no sostienen relaciones sexuales sólo con el fin de procrear. Por ende, el sexo no determina los atributos sociales, al contrario, es la cultura la que ayuda a determinarlos. Es decir, lo que significa tener "un pene" o "una vagina" lo determinan las sociedades y, por consiguiente, las culturas.

A las formas de significar culturalmente el sexo en los individuos se les llama género. En la tradición judeocristiana, el ser de "género masculino" se atribuye a aquel individuo que posee un pene, mientras que el ser de "género femenino", a quien posee una vagina. El género concebido como "lo masculino" y lo "femenino" no está dado por la naturaleza, es una construcción social. Salvatore Cucchiari (1996) sostiene que hubo una etapa en el desarrollo evolutivo del hombre donde no existía la noción de género, y que ésta se fue consolidando hasta llegar a posicionarse jerárquicamente, de modo tal que la dicotomía biológica o sexual es más un producto de la ideología de género que de lo contrario. Esto significa que los individuos no nacen mujeres o varones - culturalmente hablando-, sino son construidos gracias a una serie de prescripciones, regulaciones y tabúes creados por los hombres y para los hombres y mujeres. En consecuencia, Cucchiari argumenta que la idea de la heterosexualidad responde más a los esquemas culturales que a la biología misma de los genitales; para ello dice que los pueblos han configurado el género de lo imaginario erótico de manera plástica:

\footnotetext{
Hay mucha variación entre una cultura y otra en el ámbito erótico, al igual que en otros aspectos de sistema de género (Pomeroy, 1969: 4-6; Marshall y Suggs, 1971: 206-217). La gama abarca desde los pueblos como los etoro de Nueva Guinea, que de mala gana recurren al sexo heterosexual (Kelly, 1976), hasta la tradición judeocristiana, que insiste fóbicamente en él. La variación en el registro etnográfico sugiere que la sexualidad humana es plástica y no está sujeta a patrones genéticos u hormonales rígidos, sino determinada por las áreas simbólicas y del aprendizaje del cerebro (Cucchiari, 1996: 194).
}

Si "los etoro... de mala gana recurren al sexo heterosexual", ¿cómo explicamos que la heterosexualidad sea el modelo ideal en las sociedades contemporáneas en Occidente? El heterosexismo es "la creencia en la inherente superioridad de un modelo para amar y, por consiguiente, su derecho de ser impuesto" (Lorde, 1984: 45). El heterosexismo genera la homofobia, la cual entiendo como el poder de unos para nominar a los otros que se escapan del modelo heterosexista y hacer operativas acciones que buscan la supresión de esa diferencia.

La homofobia, constructora de la idealización de la heterosexualidad, se fue gestando poco a poco. Dentro de la historia de la sexualidad en Occidente encontramos que en torno a la homosexualidad se ha tejido una serie de discursos que han tenido una tendencia: la de hacer de la heterosexualidad un modelo superior de relaciones sexuales entre géneros - masculino y femenino- $e$, incluso, de que la identidad de género debe conformarse con cualidades y características dicotómicas y culturales asignadas según los genitales. Es decir, que tanto "hombres" como "mujeres" tienen, por su condición biológi$\mathrm{ca}$, una serie de atributos culturales que se manejan bajo el supuesto de ser otorgados por la "naturaleza". 


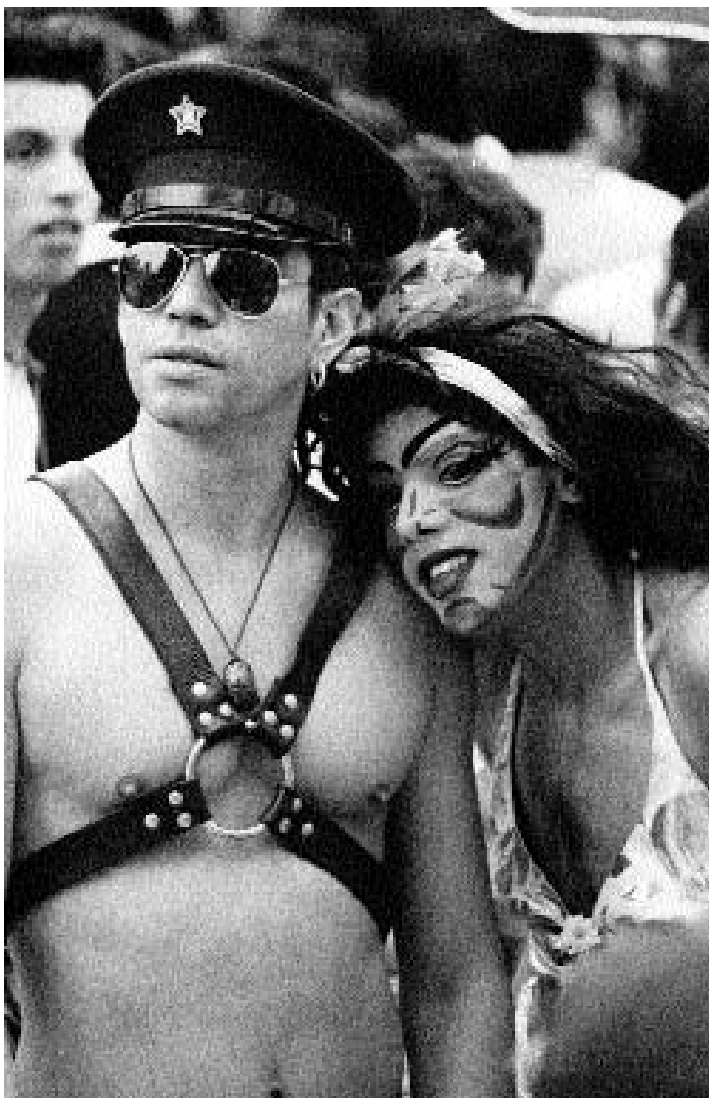

Sin título, Ricardo Ramírez Arriola

Sin embargo, cabe aclarar que el orden social no forma parte de la naturaleza de las cosas y no puede derivarse de las leyes de la naturaleza (Berger; Luckmann, 1998). Pues el orden social humano existe solamente como producto de la actividad social de las personas y éste cambia según las culturas y las sociedades.

La homofobia no apareció de un día para otro en Occidente. En la Grecia antigua, Platón y Safo elogiaban a los homosexuales (mujeres y hombres) y escribían sobre los amores y desamores entre los individuos de un mismo sexo. Entonces, ¿por qué hay un discurso que estigmatiza a los homosexuales? John McNeill (1979) establece que el argumento de la Iglesia cristiana tuvo mucho peso en la configuración de la homofobia. La Iglesia se apoyó en el supuesto de que las relaciones homosexuales eran antinaturales, pues no producían una semilla fértil; para ello se argumentó tomando como referencia la confirmación divina en el mito de Sodoma y Gomorra.

El hecho de que a las mujeres y a los varones se les exhorte a conducirse según una dicotomía sexual y de expresiones culturales binarias no es cosa del azar, al contrario, es producto de una normatividad institucional influida por el cristianismo que se difundió en Occidente. Sin embargo, ésta no fue lineal; la imposición del orden social sobre el otro — homosexual— fue dándose en procesos graduales y no con presupuestos uniformes, sino ambiguos y contradictorios. La homofobia inicialmente fue avalada por la Iglesia cristiana, no obstante, su poder ideológico y coercitivo permeó a otras estructuras de poder. La religión cubrió las diferentes conciencias de los individuos al punto de imponerse el heterosexismo en otros espacios fuera del dominio religioso.

Por consiguiente, las taxonomías creadas para comprender lo que encerraban los mundos, los "propios" y los de los "otros", quedaron impregnadas por la visión heterosexista. Así resulta que a los homosexuales se les aludía como sodomitas, hermafroditas, afeminados, pederastas, etcétera.

\section{LA HOMOFOBIA. ACCIONES PARA SUPRIMIR LA DIFERENCIA}

En el siglo XIX las expresiones de la sociedad consideradas como vicios o desviaciones se encontraban en la jerga de los hombres de ciencia. Carmen Núñez (1996) explica que los antropólogos criminales tuvieron un papel importante en la investigación genética de los vicios sociales, en este sentido, se argumentó que la homosexualidad era una anomalía, una enfermedad.

El estudio positivista sobre la homosexualidad se remonta a la segunda mitad del siglo antepasado. La palabra homosexual se acuñó en 1869 (Miller, 1995). Las ciencias, con sus estudios para categorizar y buscar la cura de la anormalidad que llevaba a los hombres a sostener relaciones sexuales con otros de su mismo sexo, motivaron el uso del concepto. Pero vale decir que en el lenguaje de la ciencia positivista, antes y a la par de la acuñación del concepto de homosexual, se comenzaron a usar varios 


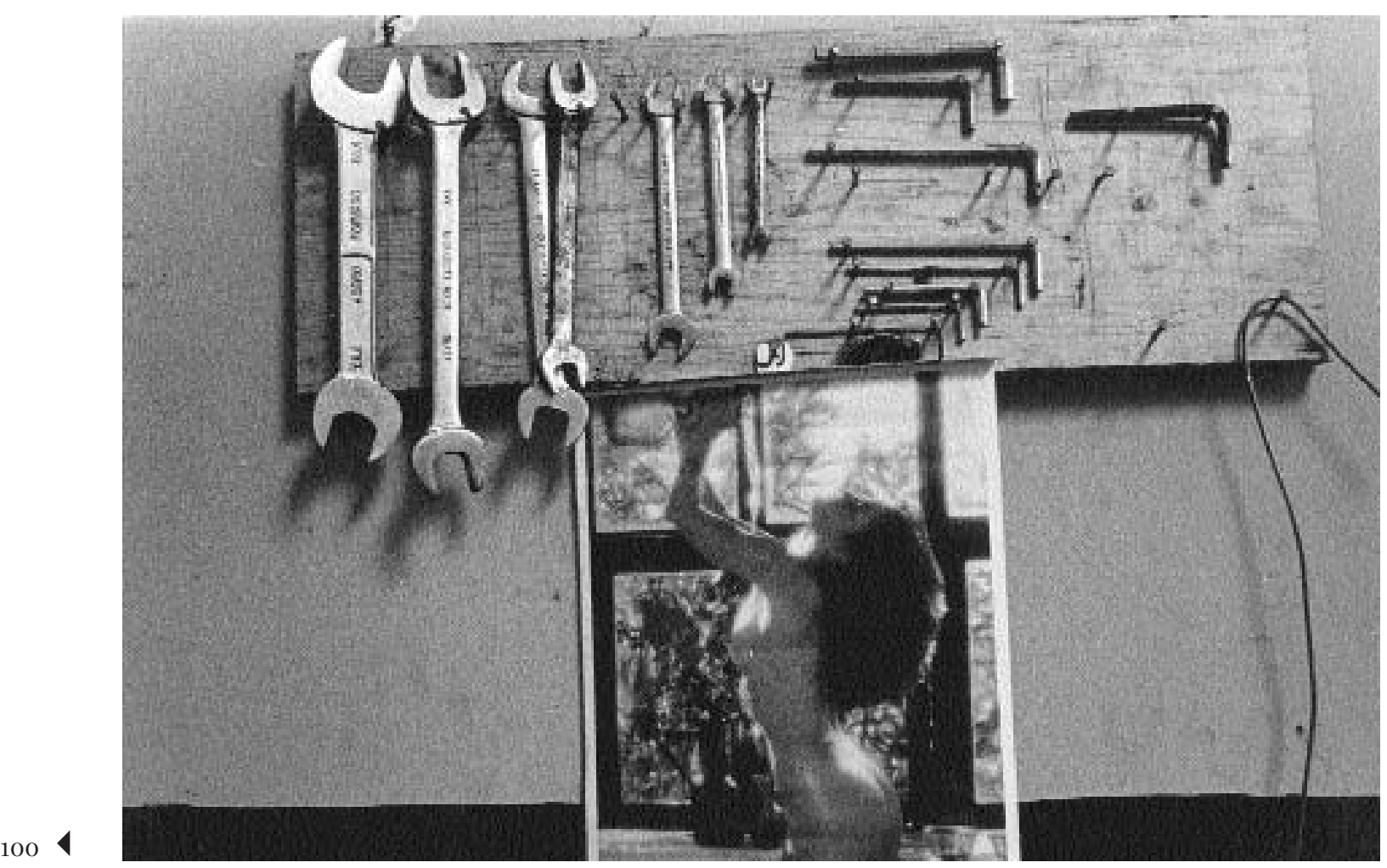

El sueño del mecánico, Jorge Acevedo

términos y cualidades para aludir a los individuos que sostenían relaciones sexuales con otros de su mismo sexo, tales como:

- El término de pedófilo (de pedofilia: ${ }^{1}$ amor por los muchachos) empleado por Claude François Michéa (1849) para definir a los practicantes de esta "perversión" como "hombres afeminados" que buscaban relaciones sexuales con individuos de su mismo sexo. ${ }^{2}$ Para el doctor Ambroise Tardieu (1857), ${ }^{3}$ miembro del cuerpo consultivo de higiene pública francesa, los pederastas contravenían la higiene y su morfología permitía al médico reconocerlos: el ano, las nalgas, el pene,

\footnotetext{
${ }^{1}$ En la actualidad este concepto se usa para referirse a los individuos que sostienen relaciones sexuales con menores de edad.

2 Citado por Hekma (1996: 215).

3 Citado por Carlier (1981), citado por Núñez (1996: 151).
}

llevaban las marcas de su degenere y pertenencia a esa especie; los pederastas copulando los asociaba a los perros, al excremento. Asimismo, el amaneramiento de sus movimientos y características negativas femeninas como el chismorreo, la vanidad, su sentimentalismo, pasividad y el apetito sexual por los hombres, eran cualidades que marcaban la personalidad de los pederastas.

- El concepto uranista, ${ }^{4}$ propuesto por el abogado Karl H. Ulrich [1860] para describir a los varones que tenían, de manera congénita e irreductible, un alma de mujer dentro del cuerpo masculino, y que sólo podían conocer el deseo y el placer de la pasión por los

\footnotetext{
${ }^{4}$ Derivado de la palabra "Venus Urania, diosa griega de los aspectos divinos o celestiales del amor" (Guasch, 1991: 76). Los sacerdotes que veneraban a Venus se vestían de mujeres (Cardin, 1989: 148).
} 
hombres viriles (Lantéri-Laura, citado por Mirabet, 1984: 131). ${ }^{5}$

- El calificativo de pervertido sexual que fue usado por Richard von Krafft-Ebing en Psycopathia sexualis (1886) y cuya taxonomía realizada sobre la homosexualidad comprendió desde la bisexualidad hasta la metamorphosis sexualis paranoica (un cierto tipo de transexualismo), influyendo así la sexología con un modelo de la homosexualidad como una forma de perversión sexual, "contraria al sentimiento sexual". 6

Núñez (1996) manifiesta que durante el siglo XIX, en la compilación exhaustiva de perversiones y delitos sexuales, la homosexualidad ocupaba un lugar más silencioso en comparación con la incontinencia, el autoabuso (la masturbación) y la fornicación. Ella explica que los burgueses y los hombres de ciencia prefirieron guardar silencio como una estrategia para no confrontar la homosexualidad en sus esferas y evitar hacer una pedagogía para prevenirla; con esto se fomentó que los homosexuales guardaran las apariencias y vivieran más tranquilos como "hijos de familia". En cuanto al safismo, Núñez dice que éste ante las autoridades sólo era un mal de los hospitales, las cárceles y el lupanar, es decir, de mujeres enfermas, ociosas y promiscuas. En consecuencia, el safismo no sería un problema de las mujeres esposas, madres e hijas de familia. También menciona que el discurso de la ciencia médica veía a las lesbianas como mujeres con cualidades masculinas. Aquí vale recalcar que muchos autores hacen mención de la ausencia de información sobre el safismo en las sociedades de los siglos pasados. Quizá esto se deba al grado de coerción, devaluación y normatividad social a la que era sometida la mujer, por lo tanto, las lesbianas prefirieron vivir una vida más clandestina que la de los varones homosexuales, incluso, me arriesgaría a especular que varias de ellas optaron por reprimir sus orientaciones homoeróticas.

Con el positivismo, las ciencias usaron a los homosexuales y otros grupos discriminados para estudiarlos; las

${ }^{5}$ Citado por Guasch (1991: 76).

6 (Cfr. Hekma, 1996: 217-226). examinaciones corporales a las que se les sometía eran humillantes. En el siglo XIX, las ciencias y las leyes se conjugaron para imponer visiones de mundo permeadas con el modelo heterosexista, prueba de ello es el mismo concepto de homosexual y la devaluación a la que era sometido el individuo que sostenía relaciones sexuales con otros de su mismo sexo.

Desde la problematización del género como una dicotomía cultural, lo que resulta especialmente interesante, por haberse creado relacionalmente con el género femenino, es la cualidad otorgada al homosexual varón, que hasta el día de hoy tiene vigencia: la de afeminado. Y en el caso de las lesbianas, el vérselas como masculinizadas o amachadas. Ambos casos ejemplifican que tanto a los homosexuales como a las lesbianas se les ha visto como individuos que cruzan las fronteras de la identidad genérica.

Es errático considerar las etiquetas afeminado y amachada como cualidades de los homosexuales y lesbianas, respectivamente, pues no las son de todos. Pero, es válido hablar de cómo se relaciona al homosexual con lo femenino, y al hombre afeminado con el ser homosexual, y de manera similar, pero en un sentido inverso, esto aplica para las lesbianas. La palabra homosexual alude a una práctica sexual, la cual tiene que ser ejercida por el individuo para adjudicarse esa categoría, no obstante, los mecanismos y procesos taxonómicos, en el caso de los homosexuales y hombres afeminados y mujeres amachadas, han sido impuestos. Desde esta perspectiva, tanto homosexual como afeminado y amachada resultan espacios separados, pero es en el imaginario de las sociedades occidentales contemporáneas donde se han construido como traslapados.

Hasta antes de la segunda mitad del siglo Xx, los procesos de la adjudicación de categorías para los homosexuales eran dinámicas de construcción social creadas por los otros y no por el nosotros colectivo-homosexual. En los discursos prevalecientes sobre los homosexuales, hasta los principios del siglo $\mathrm{xx}$, se refleja la no-existencia de una identidad homosexual autoconcebida; lo que se operacionalizaba sólo eran categorías y una sola identidad claramente definida: la del heterosexual, la cual se reificaba con la ayuda de los otros que eran vistos como anormales: los homosexuales. 


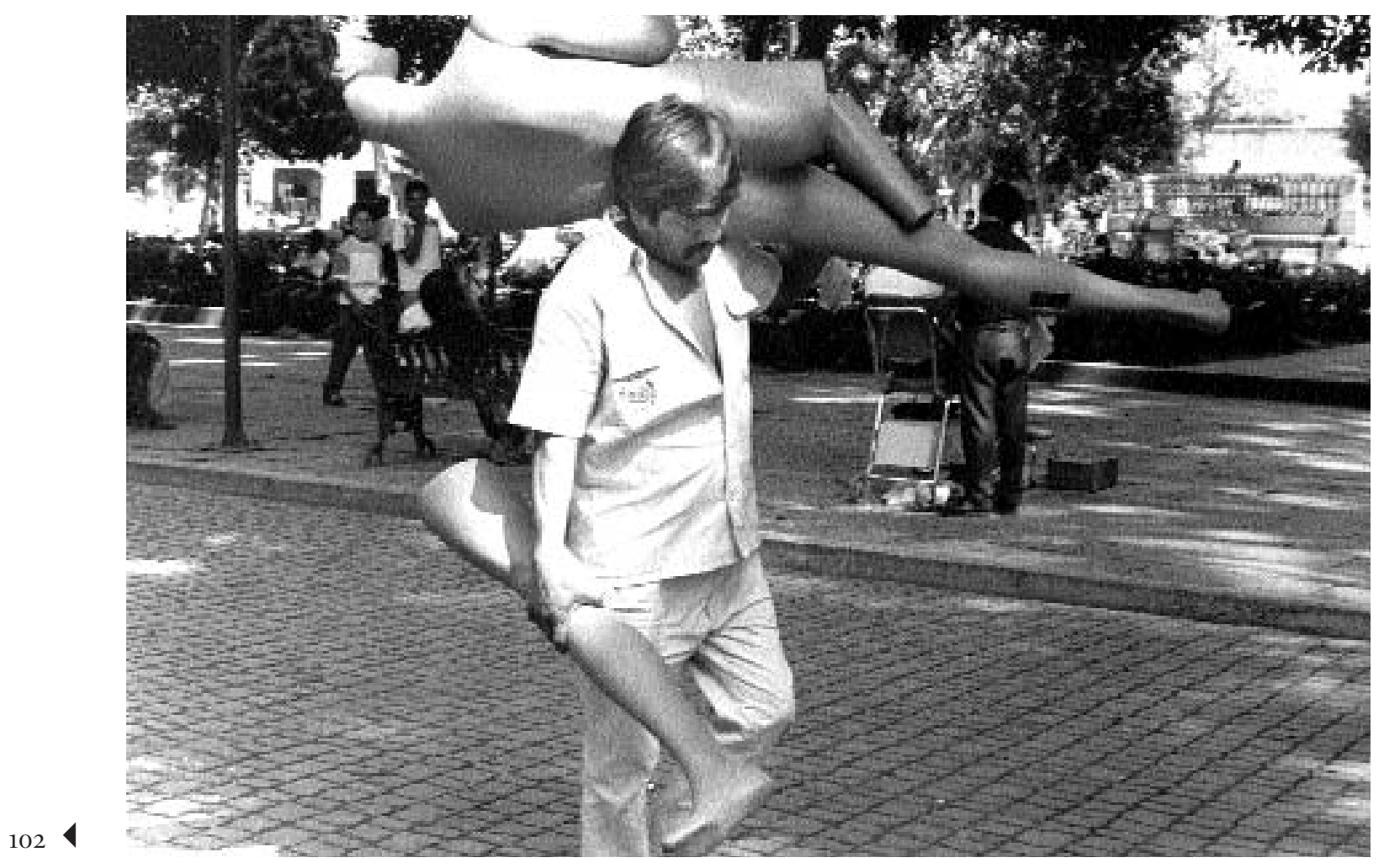

Carga femenina, Jorge Acevedo

Castells (1999) dice que las identidades pueden originarse en las instituciones dominantes, y sólo se convierten en tales si los actores sociales las interiorizan y construyen su sentido en torno a esta interiorización. Sin embargo, hasta lo que hemos visto, los homosexuales no han contado con una "identidad autoconcebida", únicamente han poseído "estigmas". Pero, ¿cómo puedo afirmar que los homosexuales no poseían una identidad? Simplemente, porque ellos todavía no se habían construido para "sí mismos". De hecho, el "homosexual" sirvió de apoyo en la construcción de la identidad del "heterosexual", la cual existía — y existe todavía - como una "identidad legitimadora", la que Castells (1999) define como aquélla introducida por las instituciones dominantes para extender y racionalizar su dominación frente a los otros actores sociales.

La "identidad heterosexual" ante los "otros-homosexuales" se ha evidenciado en la medida que ha podido fructificar en taxonomías peyorativas sobre los homosexuales, pero en ningún momento hay indicios de que los homosexuales se hayan sentido identificados con ellas. Por consiguiente, los homosexuales, hasta antes de los años cincuenta, solamente tenían estigmas legitimadores de la identidad heterosexual. En este sentido, Goffman (1986) habla de dos categorías identitarias: la identidad virtual y la identidad real. La primera responde a los atributos que supuestamente posee un individuo; mientras la "identidad real" hace alusión a los atributos que, de hecho, pertenecen a la persona. Entonces, aplicando la lógica goffmaniana, los homosexuales, hasta ese entonces, eran concebidos con una "identidad virtual" y, de antemano, estigmatizada por ser desviante al heterosexismo.

En lo cotidiano, las percepciones devaluatorias de la realidad de los otros homosexuales no se han quedado en simples taxonomías sin más fines que la representación del orden social. Se han generado estrategias pragmáticas 
para poder conseguir ese orden, donde se ha llegado, incluso, a castigar al otro por ser lo que es. Un ejemplo radical de castigo fue el asesinato de miles de homosexuales en Alemania durante la efervescencia del nazismo, ideología encabezada por Hitler. ${ }^{7}$ El nazismo, con base en una postura etnocéntrica, buscó la protección de la raza pura, eliminando a los homosexuales de la misma. Esto nos da una doble lectura; por un lado, la de los "homosexuales" como cuna de la contaminación de la raza; y por otro, la de los "homosexuales" como individuos que no pueden fomentar la reproducción de la raza. En pocas palabras, una visión heterosexista, en esencia, biologizada y reproductivamente sexualizada.

Este ejemplo de finales de la primera mitad del siglo Xx sirve para plantearnos las diferentes formas en cómo la homosexualidad era vista y vivida, y que la información científica conjugada con las legislaciones no tenía otro propósito que el de justificar los fines de unos sobre los otros: los anormales. Había más censura que averiguaciones o contenidos serios sobre la homosexualidad. Incluso en países como Suecia, ${ }^{8}$ a mediados del siglo Xx la homosexualidad era un delito (RFSL, 1996). Por otro lado, cabe enfatizar que la ciencia en ese entonces seguía viendo a la homosexualidad como una enfermedad. ${ }^{9}$ Desde esta lógica ambigua, ¿era un delito estar enfermo?

Tratar de dar una explicación a las ambigüedades en las argumentaciones que se han hecho en torno a la regulación de la homosexualidad es una tarea ardua, no obstante, lo evidente es que estas ambigüedades se hallan favorecidas por la silenciación de los estigmatizados y por los vacíos jurídicos que motivan esa regulación. Al respecto, Taylor (1993) dice que la mayoría de los discursos políticos en las naciones que buscan el reconocimiento

\footnotetext{
${ }^{7}$ McNeill (1979: 125) habla de más de 220 mil homosexuales asesinados en los campos de concentración, bajo un decreto que Himmler promulgó en 1936: "Al igual que hemos vuelto a la antigua postura germana respecto a los matrimonios interraciales, en nuestro juicio de la homosexualidad (síntoma de degeneración que podría destruir nuestra raza) hemos de volver al principio nórdico de exterminio de los degenerados."

${ }^{8}$ En la actualidad, Suecia reconoce legalmente a las parejas homosexuales con atributos similares a las de los heterosexuales.

${ }^{9}$ Hasta los años setenta se quitó la homosexualidad de la categoría de las "enfermedades mentales".
}

jurídico de sus ciudadanos, otorgándoles garantías sociales y protección legal, resultan excluyentes. Pues en los discursos políticos generalizantes que se han pregonado, el reconocimiento de los individuos que son diferentes al común de la población pasa por alto; en otras palabras, este no-reconocimiento se objetiva en la exclusión. En el caso de los homosexuales, su exclusión se argumenta con discursos biologizados y dicotómicos de género, mismos que se hacen tangibles con la biopolítica, forma en que Foucault (1989) alude a ese campo de la intervención del poder en la vida de la población de una nación, con el propósito de brindarle apoyo para que ésta perdure. La intervención se ha orientado a la reproducción de la especie y a favorecer la familia - como un núcleo heterosexual — como la base de la sociedad, lineamientos que en gran medida eran buscados también por la Iglesia cristiana y que en cierta manera se hallan reproducidos por las leyes y las prácticas políticas y sociales. Por lo tanto, al bosquejar estas miradas homófobas, la biopolítica hasta la primera mitad del siglo xx tuvo un papel muy importante en algunas sociedades occidentales, pues no sólo excluyó a los homosexuales de los derechos que les fueron otorgados a los heterosexuales, sino también atentó contra su integridad física y moral.

\section{LA SEGUNDA MITAD DEL SIGLO XX. EL FLORECIMIENTO DE LOS MOVIMIENTOS SOCIALES CRÍTICOS}

La segunda mitad del siglo xx fue cuando se formularon serios cuestionamientos a los tabúes del género y la sexualidad. Asimismo, se puede afirmar que en esta etapa, dentro de las esferas de la sexualidad hubo un reposicionamiento en las ciencias, especialmente un replanteamiento de la forma en que se concebía la homosexualidad. En el siglo XIX, Weeks (1998) dice que comenzó una "secularización del sexo", es decir, un alejamiento progresivo de los valores sexuales respecto de los valores religiosos; sin embargo, fue en el siglo xx cuando la "secularización" se acentuó en las sociedades occidentales. El nombre de Alfred Kinsey marcó un hito en este sentido. Kinsey no fue el primer científico que hizo notar que la sexualidad 
se manifestaba con prácticas diversas, sin embargo, la ayuda de los medios masivos para difundir sus informes —Kinsey — a principios de la segunda mitad del siglo $\mathrm{XX}$, sirvió para que se echara por la ventana muchos de los tabúes del género y la sexualidad.

Kinsey (1948) concluyó sus investigaciones manifestando que el 50 por ciento de la población era exclusivamente heterosexual, mientras que el resto había estado, de una u otra forma, involucrado en experiencias homoeróticas, estableciendo que la bisexualidad estaría más difundida si no existieran las restricciones sociales. Entre otras innovaciones de Kinsey se hallan el no haber buscado las causalidades de la homosexualidad y el sí haber encontrado la normalidad de la satisfacción y el placer sexual para los dos sexos, tanto en las prácticas sexuales heterosexuales como en las homoeróticas (cfr. Hooker, 1976; Núñez, 1994; Johnson; Kolodny; Masters, 1987).

Sin embargo, las investigaciones de Kinsey no fueron las únicas críticas de las restricciones sociales, también hubo condiciones contextuales que favorecieron éstas, especialmente en Estados Unidos y Europa. La integración masiva de las mujeres al mercado laboral durante la segunda guerra mundial y su establecimiento definitivo en él durante la posguerra llevó a intensos cuestionamientos la cultura patrística. Las mujeres lanzaron consignas contra las costumbres que involucraban las perspectivas de género, especialmente aquellas que se abocaban a verlas como objetos sexuales y de reproducción. Por otra parte, el hippismo, movimiento social encabezado por jóvenes que reaccionaban ante la sociedad reprimida y beligerante - pero igual de crítico que el movimiento de las mujeres - inició junto con éste sus reclamos sobre la liberación sexual, con el propósito de quitarle la etiqueta de "lo prohibido" a los tópicos sexuales y, por consiguiente, derrumbar las exclusiones y subordinaciones de las que eran objeto los individuos por ser de determinado sexo, tener equis preferencia sexual, o por ser controlados en el ejercicio de su sexualidad.

En esta efervescencia de movimientos sociales, surgieron otros que, de igual manera, alzaron la voz con serias críticas y cuestionamientos a las instituciones que normaban a los individuos. Al igual que las feministas y los hippies, aparecieron en escena las minorías raciales y los homosexuales, mostrando cada grupo sus respectivos intereses sociales y políticos. La dispersión por el mundo de estas corrientes de liberación y reconocimiento de los excluidos se contextualizó dentro de las décadas de los cincuenta y, fundamentalmente, los sesenta, época en que los medios masivos de comunicación cobraron auge dentro de las sociedades occidentales. Las sociedades que se imaginaron homogéneas y con problemáticas específicas, a través de estas nuevas alternativas de difusión se percataron de lo heterogéneas que eran y de los desniveles que en ellas se gestaban, sentimientos de desigualdad que no fueron compartidos sólo por una sociedad en específico - "la norteamericana"-, sino que encontraron eco en los individuos que habitaban más allá de esas fronteras y que se sumaron a este proyecto por una vida más justa.

\section{LA APARICIÓN DE LOS GAYS}

La primera ocasión en que la palabra gay salió con ímpetu a la luz pública fue en 1969, cuando a nivel internacional se difundió la rebelión de Stonewall, encabezada por un grupo de travestis que se lamentaba por la muerte de Judy Garland, en el Stonewall Inn (bar gay en Christopher Street, Nueva York). Este movimiento fue una protesta, un acto de resistencia civil contra la represión policiaca. Los disturbios, que duraron tres días, dieron la vuelta al mundo y sirvieron para darle fuerza a un movimiento internacional de lucha por el reconocimiento de los derechos civiles de los homosexuales (Usabiaga, 1995). Fue así, en recuerdo a este incidente, que el 25 de junio se nombró el Día Internacional del Orgullo Gay. Los homosexuales, o mejor dicho los gays, se sumaron a otros movimientos sociales para quedarse.

La palabra gay surgió como un mecanismo de autoadscripción de los homosexuales para escapar de las taxonomías peyorativas que para ese entonces les eran impuestas. Sin embargo, desde un principio el ser homosexual no implicó el ser gay, no obstante, el ser gay sí implicaba el ser homosexual. El gay tuvo como propósito inicial el reconocimiento de los otros, resultando ser una minoría social más que buscó un trato igual al de ellos. 


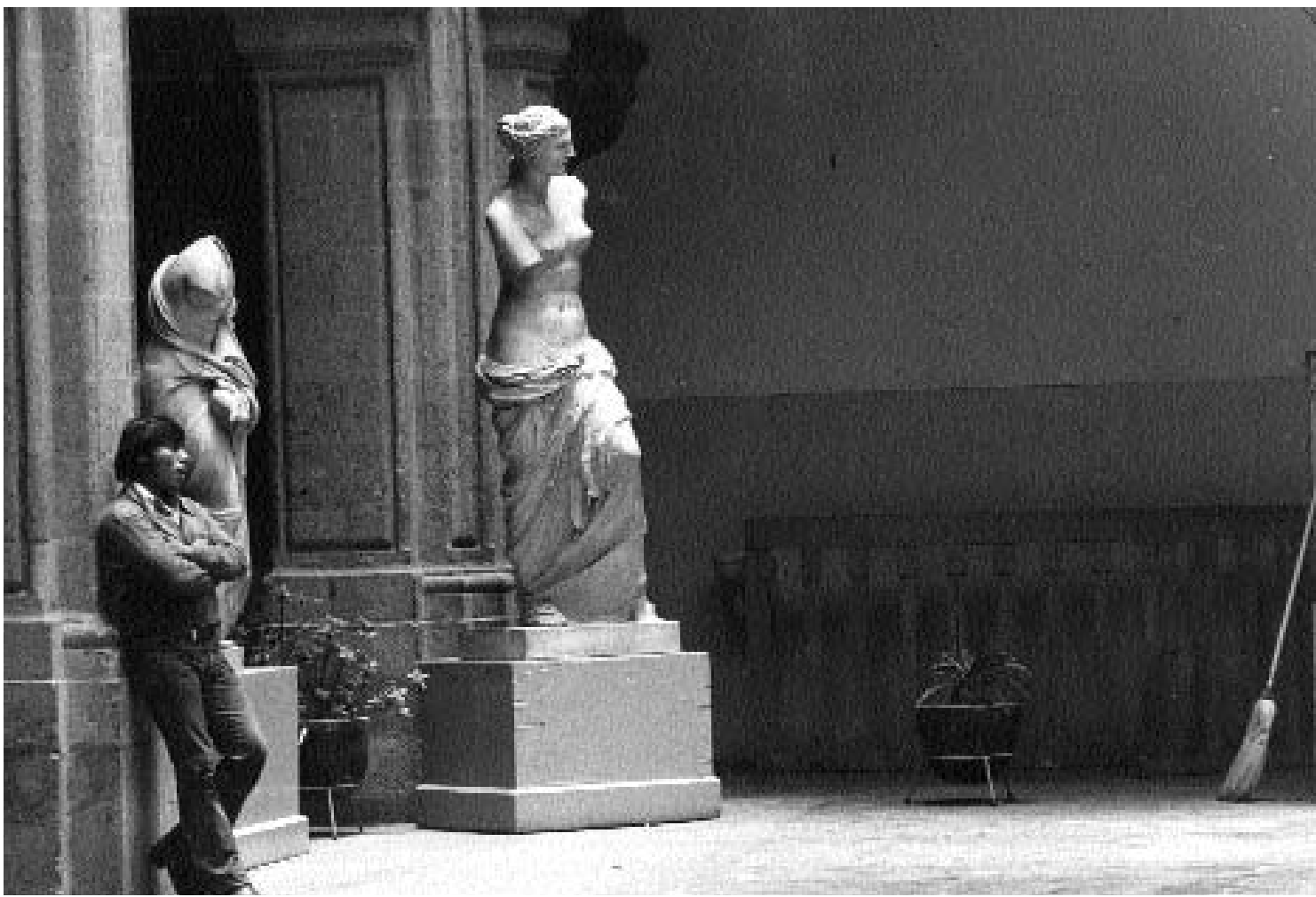

Limpieza general, Jorge Acevedo

La palabra gay se usó para borrar el estigma ocasionado por muchas otras de las palabras y sus connotaciones con las que se aludían a los homosexuales, las cuales preconcebían la interpretación de los sujetos que se orientaban a sostener relaciones sexuales con individuos de su mismo sexo. Los homosexuales, con la palabra gay, se hicieron de una identidad.

En la identidad gay se reconocen dos niveles que Castells (1999) alude en el proceso de construcción de las identidades, pero que en la identidad gay se dieron en forma intersectada: una es la "identidad de resistencia", generada por aquellos actores que se encuentran en posiciones / condiciones devaluadas o estigmatizadas por la lógica de dominación, por lo que construyen trincheras de resistencia y supervivencia basándose en principios diferentes $\mathrm{u}$ opuestos a los que impregnan las instituciones de la sociedad; y la otra es la "identidad proyecto", que emerge cuando los actores, basándose en los materiales culturales de que disponen, construyen una nueva identidad que redefine su posición en la sociedad y, al hacerlo, buscan la transformación de la estructura social.

Los homosexuales, como parte de un movimiento político que buscaba la reivindicación de sus derechos, dejaron entrever su "identidad proyecto", sin embargo, el "ambiente"10 o "gay scene", como un espacio social, se ha configurado como una "identidad de resistencia". Dicho espacio, si no de forma cabal, se halla organizado institucionalmente, contando con un reconocimiento legitimado por sus actores y conformado por conjuntos de agentes, espacios y productos que circulan en sus mercados, lo cual permite ver en sus relaciones su colectividad: la gay — quizás para muchos ignorada, pero presente.

\footnotetext{
${ }^{10}$ Palabra en jerga gay para aludir al espacio social homosexual. Por ejemplo: ¿eres del ambiente?, ¿iuna disco de ambiente?, ¿eres nuevo en el ambiente?, etcétera.
} 
La tecnología mediática no sólo fue el motor de la difusión de la problemática de los homosexuales en Estados Unidos durante los años sesenta, sino que también incentivó para que en otras naciones se adoptara esa identidad como una forma de reivindicación política, social y cultural de los homosexuales. Un año después de la rebelión de Stonewall comenzaron a organizarse en diferentes puntos geográficos manifestaciones públicas gay. El impacto que ha tenido este movimiento se ha extendido. En la actualidad, estas marchas se realizan en poco menos de 200 ciudades alrededor del mundo, y en más de 30 países. En el continente americano, los países donde se lleva a cabo esta manifestación son: Estados Unidos, Canadá, Chile, Brasil, Colombia, Perú, Puerto Rico, Uruguay, Paraguay y México (Interpride Organization, 1999).

Sin embargo, la aparición de los espacios de los gays ha sido gradual. Se dice que mucha de su organización social homosexual se debe a una red de información es- tablecida en constante negociación entre los que se hacen reconocer como homosexuales. Las negociaciones son debido al marco de hostilidad en el que se han desenvuelto los homosexuales por hallarse inmersos en un ambiente heterosexista.

El espacio ganado por los gays todavía muestra etiquetamientos que se dan fuera de ese espacio, imponiéndoseles ejercicios, acciones y taxonomías devaluatorias que forman parte de las visiones de mundo que se han heredado y transmitido a los individuos, lo que lleva a los otros - heterosexuales - a ejercer su poder de censura contra los homosexuales. El rechazo hacia los homosexuales se ha hecho explícito a través de redadas violentas y ataques realizados por las autoridades y por algunos grupos ciudadanos. La censura se ha presentado como una forma de devaluación hacia las prácticas de los gays, yendo desde la prohibición hasta las argumentaciones reprobatorias sobre los estilos de vida de los homosexuales.

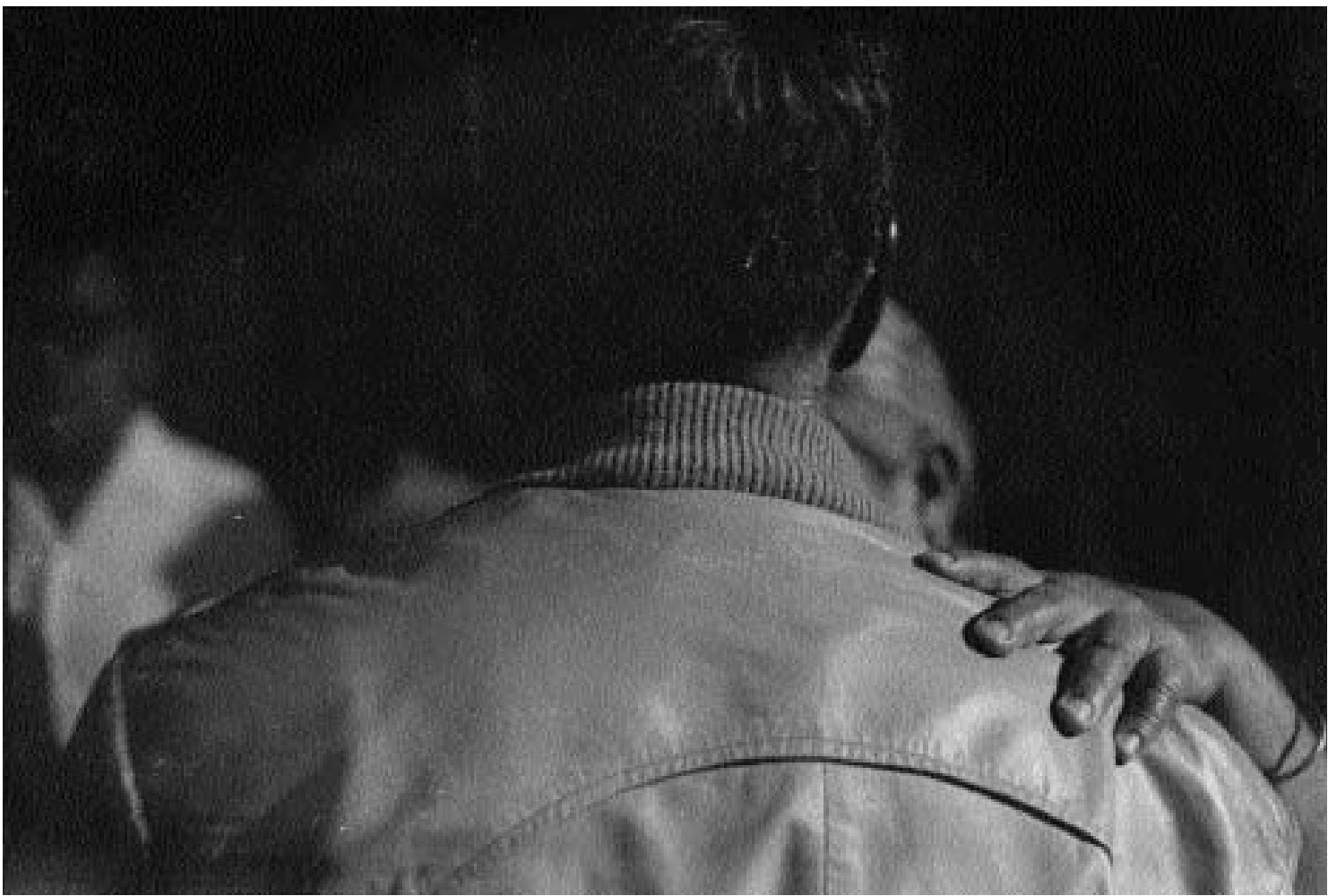

Danzón, Jorge Acevedo 
Estas acciones se han realizado por algunos sectores de la población, representantes del Estado y medios masivos. En la búsqueda de la imposición de la visión de mundo heterosexista se ha atentando contra los homosexuales, excluyéndolos de proyectos políticos que buscan la democracia y la igualdad de garantías tanto sociales como individuales, exclusiones que han llevado a estos individuos a "cohesionarse" bajo el referente "gay" como una identidad.

La identidad gay es una importación para México, sin embargo, ésta ya se encuentra en otros países, es decir, se halla en un mundo globalizado, donde ha sido usada, y por lo tanto asumida, de forma diferenciada y con proyectos muy concretos en algunos países. Por consiguiente, el ser gay se vive distintamente en cada contexto y situación geográfica. De esta forma, la vida de los homosexuales se configura adquiriendo una frontera que los separa de los heterosexuales, pudiéndose hablar de una comunidad de estigmatizados, misma que Goffman (1986) define como aquélla donde se hallan integrados individuos como grupos culturales que comparten un mismo tipo de devaluación ante los otros considerados como normales.

La separación entre los homosexuales y heterosexuales nos permite apreciar dos formas de vida, de ser, en otras palabras: dos mundos. El mundo homosexual se levanta como paralelo al heterosexual. Sin embargo, la interrogante es: ¿cómo podemos aprehender el mundo de los gays?

El mundo gay, adecuándolo a la propuesta de Renato Ortiz (1996), existe en la medida en que es vivido, pero no guarda referentes que lo ubiquen en un milieu. Sin embargo, esto no significa que se halle completamente desterritorializado; en todo caso, el mundo gay está atravesado por realidades locales, nacionales y mundiales, hallándose "tensionado por líneas de fuerza", lo que llevaría a esta identidad - "la gay" — a ser negociada, es decir, a delimitar su territorio simbólicamente, tomando en consideración la multiplicidad de actores en competencia.

La metáfora de "mundo gay" y, de manera especial la identidad gay, se ha venido fragmentando en identidades más específicas, que se engloban dentro de esta misma, lo que da a recordar que las identidades colectivas tienen como característica principal su heterogeneidad.
La identidad gay sólo se concibe en el imaginario de los sujetos, como un referente para, a partir de éste, actuar y poder negociar más identidades. Para ilustrar esto, la Marcha del Orgullo Gay (1999) en la Ciudad de México, se nombró Marcha del Orgullo Lésbico-Gay; en ella participaron lesbianas, travestis, transexuales, transgenéricos y colectividades más concretas como la de los leathers ${ }^{11} \mathrm{y}$ la de los indígenas gay (los del Colectivo Gay de Juchitán, Oaxaca). Marinella Miano (1998), quien realizó una investigación sobre el travestismo en Juchitán, deconstruiría esa colectividad gay y agregaría la presencia de otras colectividades más específicas: la de los chichifos, los tapados, los mayates, las vestidas, los muxe... Yo agregaría, en el caso particular de Colima — y con mucha seguridad, en otros lugares circundantes_ - la de las buchonas, las obvias, los buchones, las chanclas, etcétera.

En este juego de los actores dentro de las colectividades, lo que se evidencia es la necesidad de los espacios y las negociaciones de los mismos y de las identidades que éstos soportan. Para hablar de negociaciones se requiere de la presencia de líneas de fuerza, como nos asegura Renato Ortiz (1996), pero yo concretaría aún más la visión de líneas de fuerza al enmarcar la identidad gay en un campo, un campo de fuerza...

\section{UNA REFLEXIÓN FINAL: LA ESTRUCTURACIÓN DE UN CAMPO DE FUERZAY LA IDENTIDAD GAY}

Una constante que es visible en las percepciones en torno a los homosexuales, al menos hasta la primera mitad del siglo xx, es la silenciación que hay de éstos, quienes al parecer no tenían la fuerza ni el apoyo social para ellos mismos adscribirse categorías ajenas a los otros. De esta forma, alrededor de la homosexualidad se han elaborado discursos y prácticas cuya legitimidad defiende el heterosexismo, de modo tal que se haga de él algo normal, es decir, que todo aquel que se oponga a ello pasa al nivel

\footnotetext{
${ }^{11}$ Gays vestidos con ropa de cuero negro y cadenas, moda tipo sádica. Con su imagen tratan de defender la hipermasculinidad como parte de su identidad.
} 
de lo anormal o desviante, esto por no entrar en la categoría normativa de la heterosexualidad y del género mismo.

Bourdieu (1990) hace alusión al campo social como un espacio multidimensional de posiciones donde agentes y grupos de agentes se han distribuido, cada uno ocupando una posición jerarquizada. La jerarquía es el producto de los capitales que sean valorados en ese campo, capitales tan tangibles como los materiales y tan intangibles como el simbólico o del prestigio. Alrededor de la sexualidad humana y el género se ha configurado un campo social que inmiscuye la percepción de la homosexualidad, donde diferentes agentes (instituciones, lesbianas, travestidos, varones homosexuales, etcétera) se han posicionado gracias a una polifonía de expresiones y prácticas. Lo que hace el campo dinámico son las luchas simbólicas que se gestan en él, las cuales tienen el propósito de imponer la visión de mundo de unos agentes sobre los otros. Es así, con estos mecanismos, que este espacio es, en realidad, un campo de fuerza. La homosexualidad ha aparecido — por lo menos después del cristianismocomo una práctica social que ha sido devaluada por ciertos agentes que buscan imponer una visión de mundo como la mejor para todos: la heterosexualidad.

Para Bourdieu (1990) este panorama de las valoraciones de las prácticas tiene su origen en las percepciones del mundo social. Sin embargo, las percepciones son culturales y no responden ni a la genética ni al orden de lo "natural". Si se estigmatizó al homosexual, mucho se le debe a los defensores del cristianismo, quienes crearon y motivaron los estigmas sobre los "otros-diferentes".

La creación de los estigmas sobre un "otro" tiene la finalidad de reducir la identidad del mismo y exaltar, a su vez, la identidad de quien imputa el estigma. Es decir, el "otro-estigmatizado" es todo lo que el "yo-mismo" no desea ser. Estos mecanismos de negación y/o reducción del "otro" se han presentado en múltiples discursos elaborados en casi dos mil años de homofobia — desde la supuesta confirmación divina del mito de Sodoma y Gomorra hasta nuestros días. La imposición del heterosexismo sirvió para formar en las conciencias de los individuos formas de percepción del mundo muy arraigadas, que han generado prácticas de rechazo, hasta hoy en día, hacia el considerado "anormal".
Como se vio, los homosexuales hasta antes de los años cincuenta únicamente contaban con una "identidad virtual" formada con estigmas. Por esta razón, en los años sesenta los homosexuales se autodenominaron como gays, lo que sirvió no sólo para construirse un proyecto político, sino también para romper con una serie de taxonomías peyorativas que les habían sido imputadas. Con estas acciones reinvindicativas, los gays dejaron ver un espacio social construido por ellos mismos y, a su vez, una identidad.

Los gays han dado la cara en búsqueda de la reivindicación de sus derechos legales y garantías sociales y/o su reconocimiento cultural, y lo que han guardado en común son sus negociaciones constantes que realizan ante la homofobia, una forma de "violencia simbólica". Para Bourdieu (1990), la "violencia simbólica" es toda aquella estrategia que trate de imponer una visión de mundo como la mejor para los "otros" y que adquiere diferentes matices en nuestra sociedad: la imposición de estigmas, la segregación, la misma exclusión física y legal. O como Bourdieu dijo en una ocasión para el caso de los homosexuales: recibir un "trato diferenciado", inequitativo, por el hecho de preferir una orientación sexual diferente a la de la mayoría:

recibí [una carta] de un homosexual que trabajaba en Air France: " $\mathrm{Si}$ a mis colegas heterosexuales les hacen descuentos cuando salen de vacaciones con sus compañeras - protestaba—, por qué debo pagar una tarifa completa cuando viajo con mi compañero?" Los homosexuales son, de hecho, ciudadanos de segundo nivel. Entonces, cuando alguien enarbola la amenaza del "comunitarismo" para rechazar sus demandas, me cuesta trabajo ver en ello algo más que una auténtica mala fe, producto de un resabio católico, a menudo inconsciente y mal asumido, que autoriza una forma de discriminación. No hay para mí equívoco alguno. Es como si a los homosexuales se les negara asistir a la escuela. Es algo del mismo orden (Bourdieu, 1998). ${ }^{12}$

\footnotetext{
12 Bourdieu en entrevista por Portevin, Catherine; Pisanias, Jean Philippe (trad. Carlos Bonfil), "La transgresión gay. Entrevista con el sociólogo francés Pierre Bourdieu”, en Letra S (suplemento sobre salud, sexualidad y sida del diario La Jornada), núm 47, 1 de junio, 2000 (tomado de la revista Telerama, 12 de agosto, 1998).
} 
La homofobia no se ha gestado de la noche a la mañana. Los discursos y, en general, los mensajes con los que se han formado las conciencias de los individuos a lo largo de dos mil años, han generado un habitus "homófobo". El habitus es un sistema de disposiciones adquiridas por medio del aprendizaje implícito o explícito que funciona como un generador de estrategias, pudiendo estar objetivamente conforme a los intereses de sus autores sin haber sido concebidos expresamente para este fin (Bourdieu, 1988). En este sentido, las ideas de "ser heterosexual" se han incorporado tan extremadamente bien en los habitus de los individuos que han motivado situaciones de fragmentación y exclusión, presentadas tanto entre las colectividades de homosexuales como en las esferas heterosexuales.

Retomando la noción de habitus es posible, en parte, explicar las consensos y disensos que existen entre los individuos al momento de valorar una práctica sociosexual. Cuando los individuos que comparten un mismo estigma se encuentran los unos con los otros, se marcan recíprocamente su habitus, mismo que los hace sentirse unidos; es decir, los homosexuales se unen bajo el referente gay tras un proceso de aprendizaje que ayuda a cohesionarlos e incorporarlos en el mundo de los gays. Por otra parte, también el habitus sirve para comprender la separación de los gays en colectividades específicas: su pertenencia al mundo gay los hace sentirse identificados con esta identidad reivindicatoria, pero su habitus, moldeado por otras estructuras normativas externas y traslapables al espacio de los gays, los lleva a congeniar con o separarse de otros gays. Tal sería el caso donde lo racial, el sexo o la misma imagen sirven para generar vínculos socio-afectivos con una determinada colectividad gay: la travesti, la leather, la lésbica, etcétera. En cuanto al resto de los individuos que devalúan a los homosexuales, en general, sus prácticas tienen su origen en la mediación de su habitus eminentemente permeado por la ideología heterosexista y dicotómica de género.

Así, resulta que es en un campo social de "lo sexual" donde la visión de mundo que domina es la de sostener el heterosexismo como una práctica bien cotizada, donde los homosexuales tratan con sus prácticas y expresiones de hacerse de un reconocimiento, ganarse un lugar y conservar el mismo.

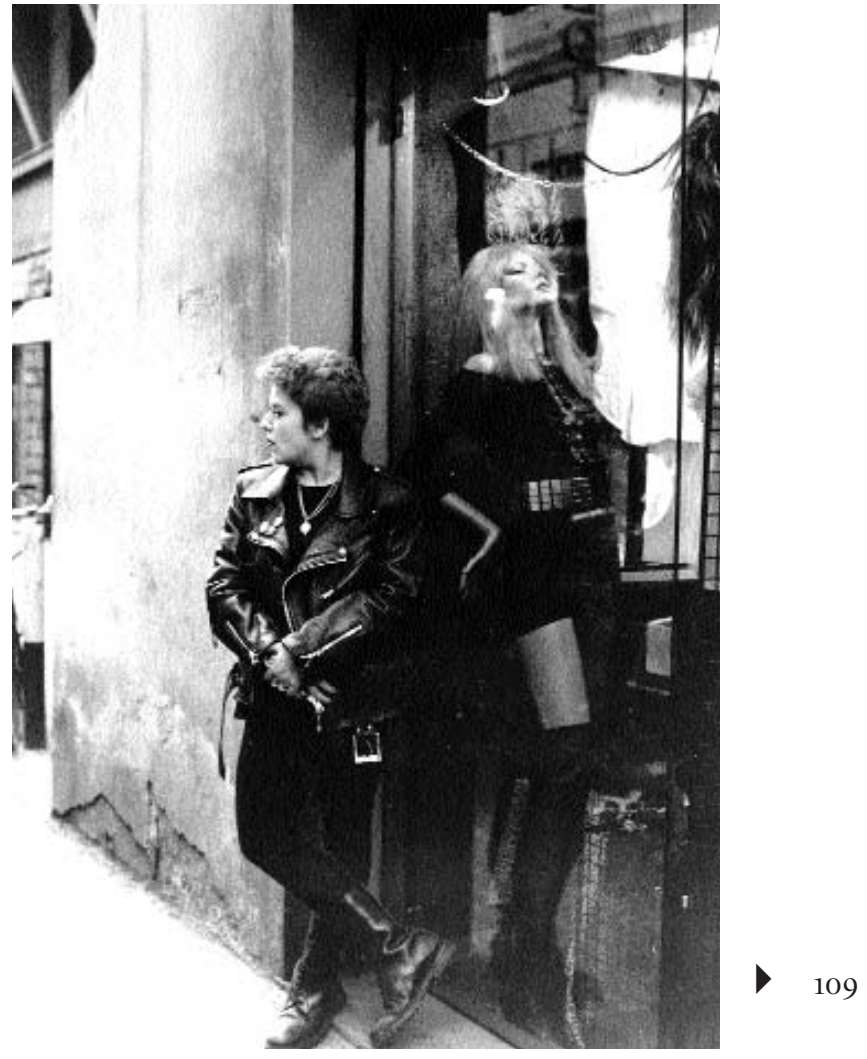

Reflejo, Jorge Acevedo

La identidad gay ha buscado su reconocimiento ante los otros. Independientemente de las particularidades en que se deconstruya esta identidad, al final de cuentas su intención primordial bien se conjuga con la insignia política y social dentro del contexto donde surgió en un inicio: la reivindicación de los sujetos excluidos: "los homosexuales". En consecuencia, al poner de manifiesto una reflexión analítica sobre esta identidad será necesario una visión multidimensional, donde lo gay ya no queda dibujado solamente por la localidad, sino que guarda sus referentes en otras dimensiones que no se hallan, en algunos casos, terrritorializadas, sino que se ubican en el imaginario de los individuos homosexuales que a diario configuran y crean — retomando las palabras de Berger y Luckmann (1998)— su microuniverso simbólico: juntos se ayudan a ganarse un espacio bajo el resguardo de la construcción dialéctica de su identidad social gay. 